\title{
Digitization of India - Impact on the BOP Sector
}

\author{
Keerthan Raj, ${ }^{1}$ \& P. S. Aithal ${ }^{2}$ \\ ${ }^{1,2}$ Srinivas Institute of Management Studies, Srinivas University, Mangalore - 575 001, INDIA. \\ E-mail: 2keerthanraj@gmail.com
}

\begin{abstract}
India is the fastest growing economy in the world. It is also the seventh largest economy in the world by GDP measure and the second largest in terms of Purchasing Power Parity (PPP). The digital Indian plan was a major step by the government in India to bring all segments into purview. It has a three pronged agenda of providing infrastructure, governance and digital empowerment to every citizen. This initiative will transform the economy of the nation and make it among the top seven countries globally to go completely digital. But, inherently this exercise was a critical need to get the vast population and the informal sector into the folds of accountability and get statistics on the informal economy in India. Although, there is no accurate figure defined as BOP for the Indian sector by the government statistical organizations, the below poverty line statistics published by the government look at people living on even less than $\$ 0.45$ per day. Such being the socio economic situation with the thrust on a lot of developmental measures and poverty alleviation methods, there has been a significant improvement in employment opportunities and as per some statistics we have seen a large number of households moving out of dire poverty. The importance of these digitization efforts is planned economic and societal growth triggered by a massive adoption of digital technologies. This paper studies the various action plans in digitization and their impact on the BOP sector in India.
\end{abstract}

Keywords: BOP, Digital India, BOP sector, Unorganized sector.

\section{How to Cite this Paper:}

Keerthan Raj, Aithal, P. S. (2018). Digitization of India - Impact on the BOP Sector. International Journal of Management, Technology, and Social Sciences (IJMTS), 3(1), 59-74. DOI: http://doi.org/10.5281/zenodo.1211434. 